\title{
Correction: Lättman, K., et al. Perceived Accessibility, Satisfaction with Daily Travel, and Life Satisfaction among the Elderly. Int. J. Environ. Res. Public Health 2019, 16, 4498
}

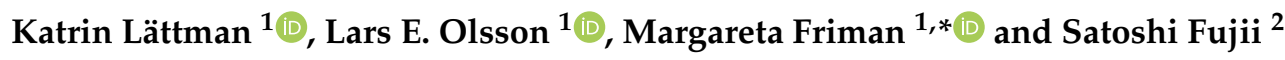 \\ 1 CTF Service Research Center, Department of Social and Psychological Studies, Karlstad University, SE-65188 \\ Karlstad, Sweden; katrin.lattman@kau.se (K.L.); lars.e.olsson@kau.se (L.E.O.) \\ 2 Kyoto University, Katsura, Nishikyo-ku, Kyoto 615-8540, Japan; fujii@trans.kuciv.kyoto-u.ac.jp \\ * Correspondence: margareta.friman@kau.se; Tel.: +46-73-460-6554
}

Citation: Lättman, K.; Olsson, L.E.; Friman, M.; Fujii, S. Correction:

Lättman, K., et al. Perceived

Accessibility, Satisfaction with Daily Travel, and Life Satisfaction among the Elderly. Int. J. Environ. Res. Public Health 2019, 16, 4498. Int. J. Environ. Res. Public Health 2021, 18, 4047. https://doi.org/10.3390/ijerph 18084047

Received: 23 March 2021

Accepted: 29 March 2021

Published: 12 April 2021

Publisher's Note: MDPI stays neutral with regard to jurisdictional claims in published maps and institutional affiliations.

Copyright: () 2021 by the authors. Licensee MDPI, Basel, Switzerland. This article is an open access article distributed under the terms and conditions of the Creative Commons Attribution (CC BY) license (https:// creativecommons.org/licenses/by/ $4.0 /)$.

\section{Text Correction}

There were errors in the original article [1], and the authors would like to apologize for any inconvenience caused. The authors regret that due to a recently observed technical error in the mobile application used to collect survey data, biased data was observed for 528 out of 2950 respondents. New analyses with the smaller sample of 2422 respondents replicated the main findings, and most conclusions are still valid.

Some minor changes were observed. The explained variance (R2) changed from 0.05 to 0.17 for satisfaction with travel (STS) and from 0.18 to 0.14 for life satisfaction (LS). The reason for this is that technical errors were found in relation to these variables, which also resulted in increased mean scores of between 0.2 and 0.4 across age groups for both STS and LS in the new analyses. In the model, paths are now stronger from perceived accessibility (PAC) to both STS (from $\beta=0.22$ to $\beta=0.39$ ) and LS (from $\beta=0.15$ to $\beta=0.31$ ), and remain significant but less strong from STS to LS (from $\beta=0.36$ to $\beta=0.13$ ). Paths from car use to STS and from gender to PAC were slightly reduced.

The previously observed moderation of age for the path between PAC and LS remains, although a slight change was observed in that the path was strongest for the old age groups, a finding explained by reduced travel and a shift in mode use when reaching the age of 75 . For the paths between PAC and STS, and between STS and LS, moderation of age are no longer observed. Moderation for the path between PT use and PAC, and between being a women and PAC were replicated, while moderation of age related to car use and STS is no longer observed. Finally, comparisons of means scores for PAC, STS, and LS across the age brackets changed from being non-significant to significant. However, the effect sizes were negligible, ranging from 0.004 to 0.008 .

In light of these new analyses, corrections have been made to several sections, such as the Abstract, Method (2.1 Participants), Results (3.1 Travel mode Use; 3.2.1. Reliability and Validity of the Latent Constructs; 3.2.2. Testing the Structural Model; 3.2.3. Testing Moderation by Age Group; 3.2.4. Comparisons of Means across the Age Brackets for PAC, STS, and LS), 4. Discussion, and 5. Conclusions.

The authors apologize for any inconvenience caused and state that the new analyses replicate the main findings, and that most of the scientific conclusions are still valid.

The original article has been updated.

\section{Correction of Figure/Table Legend}

As a consequence of the new analyses, the legend has been changed for Figure 2. by adding a note on marginally significant paths. The original article has been updated. 


\section{Correction of Figure/Table}

As a consequence of the new analyses, Figure 2., Figure 3., Table 2., Table 5., Table 6., and Table 7. have been changed. The original article has been updated.

Conflicts of Interest: The authors declare no conflict of interest.

\section{Reference}

1. Lättman, K.; Olsson, L.E.; Friman, M.; Fujii, S. Perceived Accessibility, Satisfaction with Daily Travel, and Life Satisfaction among the Elderly. Int. J. Environ. Res. Public Health 2019, 16, 4498. [CrossRef] 